\title{
Nuflo de Chaves y las estrategias de relación con los indígenas guaraníes en la conquista de Santa Cruz de la Sierra
}

\author{
Cecilia Gabriela MARTíneZ \\ Universidad de Buenos Aires \\ ceciliagmartinez@gmail.com
}

Recibido: 5 de septiembre de 2012

Aceptado: 15 de enero de 2013

\begin{abstract}
RESUMEN
Desde su llegada a América en 1541, Ñuflo de Chaves participó en expediciones hacia el noroeste del Paraguay en las que acumuló experiencias de interacción con los nativos a partir de las cuales forjó una forma particular de relacionarse con ellos que luego intentaría trasladar al área cruceña. Pero el piedemonte andino ya no era un área marginal, sino un espacio de frontera cuya ocupación debía ser legitimada frente a las autoridades virreinales del Perú. La integración de aquel territorio al virreinato implicaba a su vez la incorporación a una economía centrada en la extracción de metales preciosos, para la cual el área cruceña aportaría mano de obra indígena de las tierras bajas. Este trabajo analiza las formas a través de las cuales Ñuflo de Chaves se relacionó con los grupos guaraní-hablantes y las transformaciones que aquellas sufrieron a lo largo del proceso de conquista y colonización de Santa Cruz de la Sierra.
\end{abstract}

Palabras clave: Ñuflo de Chaves, Asunción, Santa Cruz de la Sierra, guaraníes, chiriguanos, siglo XVI.

\section{Strategies of Interaction between Ñuflo de Chaves and the Guarani Indians in the Conquest of Santa Cruz de la Sierra}

\begin{abstract}
During the twenty years that Ñuflo de Chaves lived in South America, he took part in many expeditions from Asunción to the West along the Paraguay River. In these explorations he learned a distinctive way of interaction with the natives based in permanent alliances and negotiations with the Guaraní. When he moved to the Andes foothills, he tried to keep on using these strategies, but the geographical and political proximity to the center of the Colonial economy imposed new contextual conditions that changed his relationship with the Guaraní. The paper describes the diverse experiences of relationship between Nuflo de Chaves and different Guaraní-speaking groups.
\end{abstract}

Key words: Ñuflo de Chaves, Asunción, Santa Cruz de la Sierra, Guaraní, Chiriguano, sixteenth century.

Sumario: 1. Introducción. 2. La relación entre españoles y guaraníes antes de Álvar Núñez Cabeza de Vaca. 3. Irala versus Cabeza de Vaca: estrategias encontradas de interacción (1542-1545). 4. Chaves pacificador de chiriguanos (1548). 5. Alianza de Chaves y los chiriguanos contra Manso (1559-1561). 6. Reconfiguración de las relaciones y levantamientos indígenas (1563-1568). 7. Palabras finales. 8. Referencias documentales. 9. Referencias bibliográficas.

\section{Introducción}

A principios de 1561 Ñuflo de Chaves fundó la ciudad de Santa Cruz de la Sierra, donde actualmente está emplazada la ciudad de San José de Chiquitos, en el oriente boliviano. Fue el resultado de un largo proceso de exploración con propósitos de conquista emprendido desde la Gobernación del Río de la Plata, con sede en Asunción. Desde su llegada a América en 1541 Chaves participó de expediciones hacia el noroeste del Paraguay motivadas por la búsqueda de la tierra del Candire, en las 
que acumuló experiencias de interacción con los nativos a partir de las cuales forjó una forma particular para relacionarse con ellos que luego intentaría trasladar al área cruceña. Las estrategias adoptadas por los indígenas que habitaban los alrededores del río Paraguay al momento de interactuar con los conquistadores incidieron sensiblemente en la percepción que Chaves y los asunceños tuvieron de ellos. Eso se debió en gran parte a que las condiciones del asentamiento en una región periférica como la del Río de la Plata (inferioridad numérica española, dificultades para mantener comunicación con la metrópoli y necesidad de contar con la colaboración de los guaraníes para su aprovisionamiento) dieron lugar a un vínculo basado en permanentes negociaciones y alianzas no exentas de conflicto. Esas relaciones establecidas en pie de igualdad entre conquistadores e indígenas fueron celosamente preservadas por los guaraníes del Paraguay, quienes se resistían sistemáticamente a cualquier intento de dominación por parte de los colonizadores españoles que vivían en Asunción.

Sobre la base de esa experiencia adquirida en Asunción, Ñuflo de Chaves avanzó hacia el oriente boliviano. Pero el piedemonte andino ya no era un área marginal, sino un espacio de frontera cuya ocupación debía ser legitimada frente a las autoridades virreinales del Perú. La integración de aquel territorio al virreinato implicaba a su vez la incorporación a una economía virreinal centrada en la extracción de metales preciosos, para la cual el área cruceña aportaría mano de obra indígena de las tierras bajas. Todo esto obligó a Chaves a replantear y reformular las formas de interacción con los nativos, y le imprimió una nueva dinámica a su relación con ellos. En las páginas que siguen relatamos la experiencia de Chaves con los indígenas a lo largo de los años que vivió en América considerando a éstos como parte activa en la determinación de los alcances y los límites de la conquista española. Proponemos asimismo que las estrategias a partir de las cuales los propios indígenas se vincularon con los conquistadores requieren ser entendidas en el marco de relaciones interétnicas configuradas en tiempos prehispánicos, que pudieron, según el caso, funcionar como obstáculo o contribuir a los intereses de los europeos. Finalmente, analizamos la transformación de la relación de Chaves y los asunceños con los nativos a lo largo del derrotero que los llevó del Paraguay al piedemonte andino.

\section{La relación entre españoles y guaraníes antes de Álvar Núñez Cabeza de Vaca}

Desde el momento en que los españoles de la armada de Mendoza llegaron al Río de la Plata y poblaron Buenos Aires, las condiciones para la vida en ese espacio se presentaron sumamente adversas debido a la escasez de alimentos y a la ofensiva de los indígenas. Los viajes a la costa de Brasil en busca de comida y la construcción de muros de tierra alrededor de Buenos Aires no ofrecieron soluciones duraderas, razones por las cuales optaron por la exploración de las tierras interiores, que además era una alternativa alentada por la idea de que en esa dirección se encontraría la Sierra de la Plata ${ }^{1}$. Con ese propósito, en mayo de 1536 Juan de Ayolas, teniente de gobernador

\footnotetext{
1 «Sierra de la Plata» es una de las formas en que los documentos se refieren a los lugares míticos asociados con la abundancia de metales preciosos. También se los denominaba «Reino del Rey Blanco», «Paititi», «El Dorado», «Candire», «Tierra Rica» o «Noticia Rica» (Levillier 1976).
} 
de Pedro de Mendoza, partió río arriba con tres naves y 270 hombres, entre los cuales se encontraba Domingo Martínez de Irala. La expedición de Ayolas, que primero remontó el río Paraná y siguió luego por el Paraguay, pasó por la tierra de los guaraníes, donde fueron recibidos pacíficamente y provistos de comida. No se trataba de una colaboración menor, dado que de los casi trescientos hombres que habían salido de Buenos Aires con Ayolas un tercio había muerto de hambre. Además, el puerto de Tapuá, cuatro leguas al norte de donde luego se fundaría Asunción, fue un centro activo de mestizaje español-guaraní donde algunas de las hijas del cacique Moquiracé fueron entregadas a Irala y Garci Benegas. Tan favorables condiciones alcanzadas en la tierra de $\operatorname{los}$ carios $^{2}$ los alentaron a seguir río arriba, hasta la tierra de los payaguaes, donde establecieron el puerto de Candelaria. Desde allí Ayolas se adentró por tierra hacia el oeste acompañado por 130 hombres, mientras Irala lo esperaba junto a los 33 restantes, aunque trasladado un poco más al sur de Candelaria, en tierras guaraníes, donde se sentían muy a gusto acompañados de mujeres guaraníes (Gandía 1932: 60-61). Mientras tanto en Buenos Aires, ante la falta de noticias sobre la suerte de Juan de Ayolas, se decidió el envío de Juan de Salazar Espinosa acompañado de 70 hombres. Luego de que se encontrara con Irala, y siguiendo las indicaciones de Pedro de Mendoza, fundó la villa de Nuestra Señora de la Asunción en agosto de 1537, a orillas del río Paraguay, en plena concordia con los guaraníes que habitaban esas tierras. Todo indica que el primer contacto entre españoles y guaraníes fue pacífico y cauteloso, dado que se necesitaban mutuamente; los primeros estaban interesados en abastecerse para el viaje al Candire y no podían hacerlo a la fuerza dada su inferioridad numérica mientras que los segundos, confiados en ser mayoría, deseaban intercambiar víveres por bienes que traían los recién llegados como anzuelos, peines y telas coloridas (Roulet 1993: 116).

Los guaraníes poblaban un área que se extendía entre $\operatorname{los} 22^{\circ}$ y los $25^{\circ}$ de latitud sur y entre las orillas orientales del río Paraguay y el Océano Atlántico. Pero no eran los únicos moradores de las tierras aledañas al río Paraguay, que funcionaba como un espacio de frontera con los grupos chaqueños y por donde circulaban de sur a norte numerosos grupos canoeros que controlaban la margen occidental del Paraguay, como los agaces, guatatas, yapirus, payaguás, guaxarapos pertenecientes a la familia lingüística guaycurú, que en muchos casos eran conocidos como «corsarios del río». Estos grupos dedicados a la caza y la pesca, aprovechaban además -si era necesario, de forma agresiva- los recursos agrícolas que les ofrecía la orilla oriental. Los payaguás practicaban un intenso intercambio entre las distintas poblaciones del área o simples piraterías en las poblaciones guaraníes y además servían de vigías fluviales para los grupos de tierra adentro, como los nohagues y los mbaya, menos cercanos al río, que cohabitaban el interior chaqueño con los guanás o chanés, de la familia lingüística arawak (Susnik 1978: 10). Por último, más al norte, las poblaciones de los xarayes se aliaban con los canoeros guerreros para resguardarse de los ataques de los guaraníes.

Entonces el espacio del río Paraguay y alrededores no estaba exento de conflictos. Es ahí donde llegaron los conquistadores del Río de la Plata en busca de un sitio se-

2 Las fuentes asunceñas del siglo XVI utilizan «carios» y «guaraníes» como sinónimos (Combés 2010: 86). 
guro y bien provisto de alimentos donde asentarse. En esas circunstancias no tardaron en sellarse alianzas entre conquistadores e indígenas, como la unión hispano-guaraní de 1539 por la que Domingo Martínez de Irala condujo una incursión contra los agaces e hizo posible que 300 auxiliares carios lo acompañaran al puerto de Candelaria a esperar noticias de Ayolas (Roulet 1993: 133-134). Sin embargo dichas alianzas establecían delicados equilibrios que se encontraban constantemente amenazados por el afán de extracción de excedentes por parte de los españoles y la resistencia que oponían los guaraníes (Roulet 1993: 119-138).

La inicial inferioridad numérica de los conquistadores jugó a favor de la armonía entre ambos grupos, a la vez que el arribo de nuevos contingentes españoles trastocó la concordia inicial en la medida en que llegaban con la intención de establecer una dominación efectiva sobre los nativos. La presencia del nuevo gobernador Álvar Núñez Cabeza de Vaca, que llegó para relevar a Domingo Martínez de Irala en la gobernación a partir de 1542, impuso la necesidad de los guaraníes de sellar acuerdos con el nuevo referente español y pronto puso en evidencia la distancia entre la estrategia integracionista de Irala y la política de conquista de Cabeza de Vaca.

\section{Irala versus Cabeza de Vaca: estrategias encontradas de interacción (1542- 1545)}

El asentamiento español en Asunción y la posibilidad de los conquistadores de sostener allí una presencia permanente estuvo determinado por la buena predisposición de los nativos. No obstante, no se trató de una aceptación pasiva de condiciones impuestas por los españoles, sino del ejercicio permanente de negociaciones, colaboraciones y demostraciones de fuerza mutuas. Al poco tiempo de asumir el cargo de Gobernador del Río de la Plata, a inicios de 1542, Álvar Núñez Cabeza de Vaca recibió la visita cordial de los indios agaces, «enemigos de los xrisptianos e destos yndios carios vasallos de su magestad». Cabeza de Vaca los recibió y acordó no agredirlos a condición de que no les hicieran más guerra a los guaraníes. Como garantía del acuerdo «dieron ciertas hijas e parientas suyas las quales el señor gobernador mando dotrinar e ynstruyr en la santa fee catholica». Además de la entrega de mujeres por parte de los agaces, el pacto incluyó el trato amistoso mutuo y la entrega de regalos (Colección GGV, Tomo 45, Doc. 914: 26).

Los agaces no fueron los únicos que se presentaron. En el mes de julio de 1542 Pedro de Mendoza, Francisco Ruiz Mayraru, Juan de Salazar, Adrián y Gonzalo Mayraru, Lorenzo Moquiraci con otros caciques guaraníes presentaron quejas contra los indios guaycurues que mataban a sus parientes, los corrían de sus tierras, y le pidieron protección por ser ellos indios vasallos del rey y convertidos al cristianismo (Colección GGV, Tomo 45, Doc. 914: 27). Pocos días después Álvar Núñez Cabeza de Vaca salió con doscientos hombres a hacer la guerra a los guaycurúes, a quienes venció y tomó prisioneros.

El entramado de alianzas y acuerdos de paz celebrados por los conquistadores se volvía débil en la medida en que ayudar a un grupo significaba ir en contra de los intereses del otro. Por eso la noche de su partida a la guerra contra los guaycurúes las 
hijas y parientes de los agaces, que habían sido entregadas como rehenes en signo de paz, se escaparon y la noche siguiente sufrieron ataques de una partida de canoas agaces, rompiendo de esa manera la paz acordada anteriormente (Colección GGV, Tomo 45, Doc. 914: 31).

El pacto entre agaces y españoles se vio resentido con la alianza hispano-guaraní en contra de los guaycurúes, por lo que Cabeza de Vaca decidió entonces enfrentar a los agaces por haber roto el pacto de paz que tenían (Colección GGV, Tomo 45, Doc. 914: 32). Mientras, los yapirus llegaban a Asunción a sellar un tratado de amistad. El gobernador, por su parte, decidió liberar a un prisionero guaycurú para que le comunicara a su líder su voluntad de volver a sellar la amistad entre ambos. El gesto de Cabeza de Vaca fue bien recibido por los caciques guaycurúes quienes se presentaron ante él para sellar la paz. A cambio el gobernador liberó prisioneros y les obsequió algunos bienes «con que fueron muy contentos» (Colección GGV, Tomo 45, Doc. 914: 32). Álvar Núñez demostraba a través de este gesto su voluntad de restablecer la paz con los guaycurúes, a quienes había atacado en cumplimiento de un pacto sellado con los guaraníes. La situación era compleja dados los conflictos preexistentes entre los pobladores de los alrededores del río Paraguay; acordar la paz y la ayuda mutua con unos implicaba la enemistad con otros: ningún acuerdo de paz resultaba definitivo.

La relación con los grupos canoeros, yapirus, agaces y otros, considerados enemigos de los guaraníes y de los cristianos, era fluctuante. Pero la alianza con los guaraníes tampoco parecía implicar un compromiso estable de colaboraciones recíprocas, a pesar de ser cristianos convertidos y vasallos del rey. La posición de estos indios «amigos» en la relación con los españoles estaba lejos de dejarlos a merced de su ayuda, y en algunas situaciones demostraron la intención de mantener cierta autonomía. Un ejemplo de ello tuvo lugar en la misma expedición punitiva que Álvar Núñez organizó contra los guaycurúes en respuesta a la demanda de los guaraníes. En el camino los guaraníes que formaban parte de la jornada -que eran alrededor de 4.500 - atacaron a los españoles que los acompañaban en la retaguardia, a lo que siguió una arremetida contra los indígenas que incluyó disparos de arcabuces de los hombres de infantería (Colección GGV, Tomo 45, Doc. 914: 28). Los españoles no se fiaban de los indios amigos y estaban atentos ante la posibilidad de ser atacados aun cuando enfrentaban a un enemigo común.

Un episodio similar tuvo lugar a fines de 1542 cuando los guaraníes ofrecieron guiar a los españoles a la tierra de los mbayaes, lugar donde cuatro años atrás se había perdido Juan de Ayolas. Los españoles Rodrigo Gómez, Juan de Fustes y Álvaro de Chaves se ofrecieron para reconocer el camino, y salieron con una expedición al mando de Domingo Martínez de Irala que exploraría las tierras río Paraguay arriba. El 1 de diciembre de 1542 los tres hombres se separaron de la expedición en Puerto de las Piedras y partieron tierra adentro guiados por los guaraníes. Pero sólo dos semanas después se encontraban de regreso en Asunción, porque luego de cuatro días de incursionar en dirección oeste, el cacique Aracaré había arengado a los indígenas que los acompañaban a que regresaran y abandonaran a los españoles porque si daban a conocer aquel camino «avian de ser todos ellos esclavos suyos» (Colección GGV, Tomo 45, Doc. 914: 36). Lo que prometía ser una expedición exitosa, guiada por nativos que conocían la tierra, se convirtió en una trampa cuando en medio del camino 
los guaraníes decidieron rebelarse y abandonar a los españoles en una tierra desconocida e inhóspita. Para Cabeza de Vaca semejante afrenta resultaba inconcebible.

El desafío de los guaraníes a lo pactado, pero sobre todo el desconocimiento de la deuda que mantenían con los españoles, socavaba su poder. Cuando parecían avanzar en la construcción progresiva de una relación jerárquica por medio de los acuerdos de paz, las alianzas y los pactos de unión para la guerra, las reacciones de los carios asunceños los volvían a poner en una situación de paridad. Cabeza de Vaca no estaba dispuesto a aceptar esas condiciones. Por eso le envió una carta a Irala informándole que se encontraba en Puerto de los Reyes, en una expedición río Paraguay arriba para que castigara al indígena principal llamado Aracare. (Martínez de Irala 2008b [1545]: 25). Los guaraníes no tardaron en manifestarse: conducidos por el cacique Tabaré se levantaron contra los españoles, a lo que Cabeza de Vaca respondió enviando nuevamente a Irala con cien hombres a reprimir el levantamiento. No fue una tarea sencilla. Los guaraníes opusieron resistencia y cercaron sus pueblos con empalizadas. Cuatro hombres de Irala murieron y más de cuarenta fueron heridos (Martínez de Irala 2008b [1545]: 25) $)^{3}$.

La política ofensiva de Cabeza de Vaca se reiteró en ocasiones posteriores contra los guatos y los guaxarapos, a quienes enfrentó por haber atacado a los españoles tras un intercambio pacífico (Colección GGV, Tomo 48, Doc. 938). También se refleja en el poder que le otorgó a Gonzalo de Mendoza en Puerto de los Reyes para que fuera a buscar provisiones entre los pueblos de los alrededores, autorizándolo a tomarlas por la fuerza cuando fuera necesario (Colección GGV, Tomo 48, Doc. 939).

Ambos episodios tuvieron lugar en la expedición realizada por Álvar Núñez Cabeza de Vaca entre septiembre de 1543 y la Semana Santa de 1544. El gobernador no reparó en recursos para destinar a la empresa: 10 navíos, 400 hombres de su hueste y cien canoas con 700 u 800 indios carios. Era la segunda expedición río Paraguay arriba en la que participaba Nuflo de Chaves. La primera había estado al mando de Irala, un año antes. En esta oportunidad Chaves, junto con Francisco de Ribera, Antonio Posado y Juan Romero, fue uno de los consultados antes de decidir, seis meses después de haber partido, el regreso a Asunción. Los cuatro coincidieron en que no era conveniente continuar con la entrada dadas las malas condiciones de salud en que se encontraba la hueste y las ciénagas estacionales que inundaban la tierra (Colección GGV, Tomo 48, Doc. 940). Al regresar a Asunción, la alianza entre los oficiales reales y otros capitanes partidarios de Domingo Martínez de Irala terminaría con el gobierno de Álvar Núñez Cabeza de Vaca. El suceso fue conocido como una revuelta de comuneros, en claro paralelismo con los sucesos ocurridos dos décadas atrás en Castilla contra Carlos V (Gandía 1932; Elliott 1983 [1963]; Roulet 1993).

Durante su breve gobierno (entre marzo de 1542 y marzo o abril de 1544) Cabeza de Vaca había implementado una política legalista que intentaba establecer una dominación clara sobre los nativos. Lo que no había tenido en cuenta era que la

3 Para Roulet (1993: 153-161), la decisión guaraní de abandonar a los españoles era una muestra del equilibrio que deseaban mantener. Sin embargo, la reacción violenta y drástica de Cabeza de Vaca lo ubica en las antípodas de aquella lógica y de la política negociadora de Irala. A partir de esas diferencias pensamos en la existencia de un modo de hacer de los españoles de Asunción -sobre todo de Irala- con los guaraníes que luego sería apropiado por Chaves en otros espacios geográficos. 
cotidianeidad de los españoles asentados en Asunción transcurría más cerca de los indios del Paraguay que del contacto con las autoridades reales, y que una relación de dominación sobre los indígenas sólo podía sostenerse en circunstancias de mejor aprovisionamiento, de mayor fortaleza en número de hombres y de disponibilidad de armas. Tampoco había razones de peso para someterlos. No se había desarrollado una economía extractiva como la minería en Potosí o productiva con fines mercantiles, como la de las haciendas de los alrededores de Charcas. La vida de los conquistadores instalados en Paraguay transcurría entre la quimera de alcanzar las tierras del Rey Blanco, y la realidad de una economía de subsistencia sostenida a fuerza de servicios personales basados en lazos de parentesco con los nativos. Por eso, los argumentos que los comuneros esgrimieron para justificar el golpe al gobierno de Álvar Núñez incluían acusaciones de tiranía y crueldad y el temor de que los malos tratos aplicados sobre los indios les hicieran correr el riesgo de que la tierra fuera despoblada, según deja ver el testimonio de Francisco González Paniagua en 1545 (Colección GGV, Tomo 45, Doc. 946: 39).

Cuando Álvar Núñez Cabeza de Vaca llegó al Río de la Plata «hallo muchos amancebados no solamente con cristianas pero con ynfieles no tanpoco con debdas en quarto grado pero con primas y hermanas» y mandó que las echaran de sus casas muchas veces haciendo uso de la fuerza, lo que provocó descontento y rechazo (Colección GGV, Tomo 50, Doc. 960: 6). Sus intentos por revertir aquellas prácticas poligínicas le valió la enemistad de los españoles que llevaban años de mestizaje con mujeres guaraníes, que en muchos casos coronaban alianzas con caciques de los grupos que habitaban la orilla del río Paraguay. Pero a los ojos del poder real que Cabeza de Vaca representaba, los matrimonios y amancebamientos amenazaban con desdibujar el carácter de la conquista en dos sentidos. En primer lugar, porque se vulneraba la imposición de pautas culturales como la monogamia y la celebración de matrimonios con el aval de la Iglesia. En segundo lugar, porque con las prácticas que Álvar Núñez Cabeza de Vaca intentó censurar, españoles y nativos terminarían diluyéndose en un mestizaje que los igualaría, y los volvería parte de una conformación social nueva, original y desafiante a los efectos de la dominación colonial de la Corona. Por eso lo que más aprensión provocaba entre Álvar Núñez Cabeza de Vaca y sus partidarios era que

«los hermanos que tienen las yndias de qualquier cristiano no los llama el tal cristiano hermanos de mis criadas o moças syno hermanos de mis mugeres o mis cuñados suegros suegras con tanta desverguença como sy en muy legitimo matrimonio fuesen ayuntados a las hijas los tales yndios e yndias que ansi de suegros los yntitulan» (Colección GGV, Tomo 49, Doc. 946: 47).

La forma en que los propios españoles referían el vínculo que los unía a mujeres y hombres nativos de aquel lugar (cuñado, suegro, mujer) legitimaba una igualdad que Cabeza de Vaca no estaba dispuesto a tolerar. En esas condiciones resulta razonable que ambas circunstancias -el riesgo del despoblamiento de la tierra por malos tratos y la censura de las alianzas matrimoniales establecidas con los nativos- fueran el puntapié de la organización de un movimiento de oposición a Álvar Núñez Cabeza de Vaca. A ellas se sumaron las acusaciones de los oficiales reales de exceso de personalismo, y las quejas de maltrato hacia la hueste (Colección GGV, Tomo 47, Doc. 941). 
En pocas oportunidades contamos con evidencia directa de la participación o presencia de Ñuflo de Chaves en los años transcurridos hasta la expulsión de Cabeza de Vaca. Las informaciones de servicios redactadas veinte años después, sin embargo, nos permiten reconstruir su recorrido. Así, sabemos que participó en la entrada conducida por Irala entre octubre de 1542 hasta febrero de 1543, en la cual Rodrigo Gómez, Juan de Fustes y Álvaro de Chaves a Puerto de las Piedras fueron abandonados por los guías guaraníes mientras buscaban a Ayolas. También formó parte del grupo de hombres que acompañó a Irala al ataque a Aracaré y luego a la pacificación de Tabaré. Entre el último trimestre de 1543 y el primero de 1544 fue con Álvar Núñez en la entrada río Paraguay arriba. Allí tuvieron lugar los intercambios y los enfrentamientos con los guaxarapos y los guatos, y el otorgamiento del poder a Gonzalo de Mendoza para que buscara bastimentos entre los indígenas de los alrededores de Puerto de los Reyes.

Irala condujo la primera entrada por el río Paraguay en la que Chaves participó entre fines de 1542 y principios de 1543. Recogieron información entre los nativos de la costa del río acerca de las tierras del Candire y del mejor camino para llegar a esa fuente de metales preciosos. El resultado de la indagación fue un informe presentado por Irala al gobernador (Martínez de Irala 2008a [1543]). Para Ñuflo de Chaves se trató de la primera experiencia de exploración en tierras rioplatenses, y sin duda debió dejar una marca importante. En primer lugar porque al presenciar las estrategias de Irala para relacionarse con los indígenas tuvo la posibilidad de conocer una forma particular de establecer vínculos con éstos, en la que basaría sus propias formas para interactuar con los nativos en situaciones venideras. En segundo lugar, porque la información recogida entre los pobladores de las orillas del Paraguay sobre el reino del Rey Blanco y del Paititi como fuentes de metales preciosos debió forjar una imagen de la tierra trans-chaqueña que motivaría las expediciones futuras y se materializaría en la fundación de Nueva Asunción y Santa Cruz de la Sierra, inicialmente pensadas como «postas» en el camino al Candire.

Por encontrarse ausente en Asunción en los meses previos a la prisión de Álvar Núñez, difícilmente Chaves habría participado en la organización del levantamiento comunero contra el gobernador. Pero el hecho de que hubiera arribado a las Indias en la armada de Álvar Núñez Cabeza de Vaca no fue obstáculo para que se posicionara en el bando contrario al gobernador en el levantamiento de Semana Santa de 1544 y que sostuviera esa posición en oportunidades posteriores. Una vez que Cabeza de Vaca fue arrestado e Irala elegido gobernador, no quedaron dudas de su adhesión a la facción iralista. Cuando Juan de Salazar Espinosa -alineado con el gobernador depuesto- fue detenido luego de intentar hacer valer un poder firmado por Cabeza de Vaca a su favor para asumir la gobernación del Río de la Plata en 1545, fue Nuflo de Chaves quien salió de Asunción en busca de las naves que llevaban a Álvar Núñez a España para sumarlo al grupo de los desterrados. El posicionamiento de Chaves en la facción rebelde fue simultáneo a la construcción de una alianza societaria con Domingo Martínez de Irala, a partir de la cual asumiría un rol relevante en las iniciativas de exploración del gobierno del Río de la Plata, por el río Pilcomayo a fines de 1545 y por el río Paraguay arriba y luego tierra adentro hacia el oeste en los años 1545 , 1547,1553 y 1557. 
El enfrentamiento entre los bandos iralista y alvarista puso de manifiesto dos concepciones opuestas acerca de la forma de establecer vínculos con los nativos en el marco de la gobernación del Río de la Plata. Chaves tomó parte en la disputa y construyó una forma particular de vincularse con los nativos, que adoptaría en otros contextos.

\section{Chaves pacificador de chiriguanos (1548)}

Luego del envío de Álvar Núñez Cabeza de Vaca a España, Chaves participó de nuevas entradas desde Asunción hacia el oeste con el fin de encontrar el camino que lo condujera a la Noticia Rica. Enviado por Domingo Martínez de Irala, en octubre de 1546 partió a explorar la tierra de los mbayas junto con cincuenta españoles y tres mil «indios amigos». En marzo del año siguiente condujo a treinta hombres en la expedición por el río Aracuay (Pilcomayo). Pero el intento que cambiaría la perspectiva de los asunceños comenzó a fines de 1547, cuando entraron tierra adentro desde el puerto de San Fernando y llegaron al piedemonte andino, hasta las tierras de los alrededores de Charcas, ya conquistadas por españoles. Chaves asumió entonces el rol de embajador de la gobernación del Río de la Plata y viajó a la Ciudad de los Reyes para entrevistarse con el gobernador del Perú. En el camino tuvo lugar un curioso episodio relatado en repetidos informes de los servicios de Nuflo de Chaves: al llegar al piedemonte encontró a los chiriguanos de la cordillera enfrentados con vecinos y encomenderos de La Plata, Pedro de Portugal, Martín de Almendras y Juan Ortiz de Zárate. Chaves «los puso de paz y saco a los caciques al peru y les hizo dar a los vezinos sus hijas e hijos para que tuviesen la paz con ellos» (Colección GGV, Tomo 91, Doc. 1402: 16-17 [año 1561]). Si bien el documento no deja ver con claridad que el matrimonio fue la modalidad a través de la cual selló la paz entre chiriguanos y encomenderos de Charcas, la experiencia previa de Chaves junto a Irala nos sirve de indicio para pensar en que efectivamente la estrategia de pacificación elegida por Chaves fue la del establecimiento de lazos de parentesco entre indígenas y españoles a través de la alianza matrimonial.

La información de servicios en la que se relata este episodio intenta resaltar sus dotes de pacificador y mostrarlo como un capitán con experiencia en el trato con los chiriguanos, dado que fue redactada unos meses después de haber fundado Santa Cruz de la Sierra. Ñuflo de Chaves, nombrado teniente de gobernador de García Hurtado de Mendoza, intentaba dar cuenta de antecedentes que ante la ausencia del titular de la gobernación de Mojos lo mostraran merecedor de ese cargo. No obstante estas salvedades, nos interesa resaltar la estrategia de mediación entre los caciques chiriguanos y vecinos encomenderos de Charcas, basada en la celebración de matrimonios entre las hijas de los primeros con los segundos. La larga experiencia en negociaciones con los guaraníes del Paraguay lo hacía poseedor de un conocimiento sobre mecanismos de mediación y pacificación inimaginables entre los encomenderos de Charcas, para quienes la amenaza de los chiriguanos era un problema desde hacía mucho tiempo y al que contraponían estrategias ofensivas o defensivas, producto del paradigma de dominación y explotación de recursos del cual formaban parte. Para 
el Licenciado La Gasca, por ejemplo, la fundación en 1549 de una nueva ciudad en Tucumán encomendada a Juan Núñez del Prado permitiría defender a los indígenas de Charcas de los chiriguanos, sujetarlos y suprimir la costumbre de antropofagia que les atribuían. (La Gasca 1921 [1549]: 205-206) ${ }^{4}$.

Los chiriguanos representaban un problema para los españoles de Charcas en la medida en que amenazaban una estructura productiva inserta en un sistema económico colonial que operaba otorgando recompensas a los conquistadores y excedentes para la Corona. En cambio, para los españoles de Asunción, los guaraníes constituían sus principales aliados en un espacio aislado y en el marco de una economía de subsistencia. La mirada que los conquistadores de cada núcleo colonizador podían tener respecto del mismo grupo de nativos estaba condicionada por la trayectoria particular de cada uno en América y por las motivaciones e intereses a los que respondían. A su vez, los guaraníes y los chiriguanos también asumían posiciones disímiles en cada caso. La convivencia con los españoles de Asunción y las alianzas que sellaban con ellos frente a los grupos adversarios de la costa del Paraguay tendían lazos de reciprocidad entre unos y otros que no son tan evidentes entre los chiriguanos de la cordillera y los españoles de Charcas. En este último caso, la relación entre ambos anclaba en la competencia por la ocupación del territorio y el acceso a fuentes de metales, lo que los convertía en adversarios.

En espacios geográficamente distantes, la aproximación de Chaves a los nativos tenía lugar a partir de de las pautas de interacción que había elaborado sobre la base de su experiencia asunceña. Aun cuando carios y chiriguanos no eran estrictamente el mismo grupo, la unidad lingüística y la continuación de las migraciones guaraníes al piedemonte andino con las expediciones españolas en busca de la tierra del Candire contribuyeron a sostener una continuidad en el tipo de vínculo entre los conquistadores asunceños y estos pueblos. Si además pensamos al área cruceña como un espacio de encuentro e intercambio entre los nativos que habitaban las áreas del Chaco y de Mojos, desde la cordillera hasta el río Paraguay (Combès 2010), podemos aventurar que entre los moradores de esa región circulaba cierta información referida a los españoles que propició las condiciones para tender nuevas alianzas en el espacio piedemontano. De esta manera es posible entender la secuencia de sucesos de interacción entre chiriguanos de la cordillera y asunceños en la expedición de 1557-1561, que finalizaría con la fundación de Santa Cruz de la Sierra.

\section{Alianza de Chaves y los chiriguanos contra Manso (1559-1561)}

Más de dos años después de haber partido de Asunción, Ñuflo de Chaves y sus hombres llegaron a los tamacocíes y el 1 de agosto de 1559 fundaron la villa de Nuestra Señora de la Nueva Asunción en el piedemonte andino, asentamiento que luego se conocería como La Barranca. La expedición había partido en febrero de 1557 con 25 bergantines y 158 españoles de a pie y a caballo con el mandato del gobernador del

4 Por la fecha estimamos que se refiere a la población de El Barco, que tuvo lugar en 1549, durante el período de gobierno del pacificador La Gasca. 
Río de la Plata, Francisco Ortiz de Vergara, de poblar los Xarayes -región situada río Paraguay arriba, trescientas cuarenta leguas al norte de Asunción-. Pero la expedición comandada por Chaves y secundada por su socio Hernando de Salazar se desvió del objetivo señalado y se dirigió tierra adentro hacia el oeste. Ambos capitanes abrigaban motivaciones más ambiciosas que las de asegurar el aprovisionamiento de alimentos de Asunción. Los relatos sobre la tierra del Candire, el Paititi y el Rey Blanco, oídos a lo largo de los años que llevaban en América, habían calado hondo en sus aspiraciones. Por eso, la nueva población fundada entre el Guapay y las primeras estribaciones andinas funcionaría como base de operaciones y lugar de aprovisionamiento para seguir camino en dirección noroeste en busca de la tierra de los metales («Documentos referentes...» 2008 [1561]: 110). Hasta entonces habían contado con la ayuda de los guaraníes del Paraguay -los itatines- que los habían acompañado a través del Chaco y guiado hasta ese lugar. Para seguir necesitarían que los pobladores locales oficiaran de guías. Por eso encomendó a Diego de Mendoza que juntara «yndios amigos guaranies para su ayuda y guia» («Documentos referentes...» 2008 [1561]: 110). Nuevamente los asunceños echaron mano al recurso de la alianza o la amistad; en esta oportunidad, con los chiriguanos de Vitupué 5 .

Estos primeros momentos de relación entre Chaves y los guaraníes cordilleranos no fueron conflictivos. En ese sentido marcaron un amplio contraste con los conflictos que los chiriguano mantenían con los españoles de Charcas. Diego Mendoza no llegó a encontrarse con los guaraníes de la cordillera porque antes se cruzó con el capitán Andrés Manso, que provenía de Charcas, desde donde había sido enviado para conquistar esas tierras y poner fin a los ataques de los chiriguanos sobre las haciendas de los alrededores de La Plata (Hurtado de Mendoza 1921 [1560]: 348). Mientras la expedición de Chaves llegaba con la intención de establecer una base de operaciones para seguir avanzando en el camino hacia el Candire, la expedición de Manso iba con el mandato de ocupar las tierras habitadas por los chiriguanos, y proteger la frontera de Charcas.

El encuentro entre Ñuflo de Chaves y Andrés Manso inmediatamente se volvió un conflicto abierto en el que ambos conquistadores disputaban el derecho de poblar aquella tierra. Ante la dificultad para resolver a quién correspondía tal derecho, acordaron que Chaves viajaría a la Ciudad de los Reyes mientras que Manso se quedaba con los hombres de ambas huestes a la espera de la provisión que dictara el virrey. Por su parte, los chiriguanos de Vitupué no tardaron en definir su posición. Cuando Chaves regresaba de Perú con las provisiones para la gobernación de Mojos, a la altura de Pojo, frontera con los chiriguanos, envió en una misiva el resultado de su entrevista con el Virrey. Al poco tiempo recibió noticias de que Manso estaba rebelado y amenazaba con matar a los hombres de la hueste asunceña que se habían quedado en Nueva Asunción. Ante el peligro de ser atacados por Andrés Manso los hombres

\footnotetext{
5 Entre los guaraní-hablantes que migraron desde Paraguay hacia el oeste se distinguen varios grupos. Mientras los que se asentaron al este y noreste de Santa Cruz la Vieja (los itatines) pronto fueron designados como «guarayos», el nombre «chiriguanaes»-castellanizado en chiriguanos- se siguió utilizando para hacer referencia a los grupos de la cordillera. Entre estos últimos los españoles distinguían a los del norte, próximos al río Guapay, que formaban la «provincia» de Vitupué, y los de Condorillo, cercanos al río Parapetí (Combès 2010: 136).
} 
de Chaves se refugiaron en un «bohio de yndios». Al llegar al asiento de Vitupué, Chaves encontró diecinueve hombres de su hueste que habían ido en busca de amparo frente a la amenaza de ser atacados por Andrés Manso que hacía demostraciones de fuerza armado y con cincuenta hombres «con sus arcabuzes y mechas encendidas» («Documentos referentes...» 2008 [1561]: 111).

En esa instancia, los hombres de Chaves confiaban más en los guaraní-hablantes asentados en el pie de la cordillera que en los compatriotas que levantaban armas en su contra. El peso de la experiencia de alianzas pretéritas entre asunceños y guaraníes era evidente, y contrastaba con la competencia que animaba y contraponía a los grupos de españoles provenientes desde distintos núcleos conquistadores.

Una vez resuelto el conflicto con Manso, que fue enviado preso a Charcas, los españoles de Asunción suspendieron la exploración del camino a la Noticia Rica y salieron a pacificar la tierra. Los nativos habían reaccionado a los daños que les causaron Manso y sus hombres quienes, «quemando y matando y cortando mienbros a muchos de los naturales sin culpa», habían causado un estado de desasosiego tal que amenazaba la subsistencia de los españoles de Santa Cruz («Documentos referentes...» 2008 [1561]: 112).

La estrategia de Manso estaba lejos de perseguir el favor de los chiriguanos. Chaves, por su parte, probablemente partiera del supuesto de la necesidad de garantizar la convivencia pacífica. No obstante, meses después continuaban los levantamientos de los indígenas de los llanos. Los asunceños de Santa Cruz de la Sierra responsabilizaban a Andrés Manso, que había huido de la prisión de Charcas, y solicitaban se hiciera justicia frente a tantos excesos denunciados por caciques chiriguanos. Por eso, mientras Chaves reanudaba las entradas en busca del camino al Paititi, envió a Hernando Salazar ante las autoridades virreinales para solicitar la captura de Manso por los perjuicios que el mal trato a los nativos estaba ocasionándoles («Documentos referentes...» 2008 [1561]: 112-113).

La situación provocada por Manso entre los indígenas de los llanos era grave, según consta en un testimonio de Francisco Gallego, escribano de Santa Cruz, quien reprodujo el interrogatorio que le hicieron al cacique Matarapa. Enviado a Santa Cruz por mandato de Vitupué y otros caciques, este embajador se reunió con Chaves para ponerlo al tanto de la guerra que Manso estaba llevando adelante contra los indígenas de los llanos. Los de Vitupué habían sido convocados para ir a esa guerra pero siguiendo el consejo de Chaves decidieron no ir. Sí fueron Caype, Condorillo y otros caciques chiriguanos de más al sur, que sufrieron la represalia que el Manso tomó cuando le pareció que lo llevaban por mal camino. También castigó cruelmente a otros indígenas que reaccionaron huyendo o levantándose. Ante esa situación los de Vitupué querían saber lo que Chaves les aconsejaba hacer. Los caciques representados por Matarapa estaban dispuestos a matar a Manso si Chaves lo sugería, pero éste les respondió que no lo mataran ni le hicieran ningún daño y que enviaría a Hernando de Salazar para que los ayude y solucione el problema («Documentos referentes...» 2008 [1561]: 116).

De lo anterior se desprende que los de Vitupué todavía mantenían una alianza con españoles asunceños en clara oposición a Manso. Este tipo de sucesos podría ser interpretado como la variante chiriguana de la estrategia de «dividir para reinar», a 
partir de la cual aprovechaban disensiones entre conquistadores españoles para imponerse por encima del conflicto. Sin negar lo anterior, enfatizamos la importancia de tener en cuenta el trasfondo de las experiencias previas que venimos relatando de alianza y amistad entre guaraníes y chiriguanos con los conquistadores rioplatenses en contraposición con las acciones defensivas de los españoles que incursionaban en esas tierras desde el Perú. Además, señalamos la relevancia de considerar ambas estrategias indígenas - la de alianza y la de enfrentamiento- como respuesta a las motivaciones que empujaban a los dos grupos de conquistadores hacia el piedemonte andino. En esas condiciones, un eventual cambio en la situación de alguna de las partes podía precipitar un viraje en las formas de interacción.

\section{Reconfiguración de las relaciones y levantamientos indígenas (1563-1568)}

Desde 1563 comenzó a configurarse un nuevo escenario. A partir de ese año se desató un ciclo de levantamientos de los pobladores del piedemonte contra los españoles. El cambio en la relación con los chiriguanos y sus aliados chané fue percibido con claridad por los vecinos de Santa Cruz. En una información sobre los chiriguanos solicitada por el virrey Toledo en 1571, Cristóbal de Saavedra, procurador general de la ciudad de Santa Cruz de la Sierra, sostenía que él había conocido a los chiriguanos que poblaban las tierras entre Santa Cruz de la Sierra y Charcas cuando estaban en paz y tenían relaciones amistosas con ellos, aun cuando no estaban repartidos en encomienda a ningún cristiano. Sin embargo esa situación había cambiado hacía siete $\mathrm{u}$ ocho años cuando «se convocaron con los demas que estauan en la dicha cordillera y se rreuelaron y alçaron» («Información de los Chiriguanaes» 2008 [1571]: 223).

También prestó el mismo testimonio Francisco de Mendoza, vecino de Santa Cruz: que los indios chiriguanos estaban en paz y servían a los españoles de Charcas y de Santa Cruz, y que luego se rebelaron y comenzaron a hacer la guerra («Información de los Chiriguanaes» 2008 [1571]: 227).

Las cosas habían cambiado. Mientras que en 1561 las informaciones de servicios para ser gobernador de Mojos procuraban incluir pruebas de las dotes de buen negociador con los chiriguanos de la cordillera a favor de Nuflo de Chaves, siete años después Hernando de Salazar pondría énfasis en su experiencia para hacerles la guerra a los mismos grupos a los efectos de ser nombrado en el cargo que Chaves había dejado vacante con su muerte (Salazar 2008 [1568]: 170-211).

Una vez fundada la ciudad, repartidas las encomiendas de indios y pacificada la tierra de los alrededores de Santa Cruz de la Sierra, Nuflo de Chaves partió de viaje a Asunción a los efectos de buscar sus cosas y llevar su familia a la nueva ciudad. No tenemos información precisa acerca del año en que partió, pero estimamos que fue en 1563 porque a principios de 1564 el gobernador del Río de la Plata, Francisco Ortiz de Vergara, registró su llegada a Asunción. Fue en ese tiempo de ausencia de Chaves cuando se produjo el primer levantamiento registrado en la información de servicios de Hernando de Salazar redactada en 1568 (2008 [1568]: 173). A partir de ese momento tendría lugar una serie ininterrumpida de ofensivas y contraataques entre indígenas de los alrededores de Santa Cruz y vecinos de la ciudad. Cuando Chaves, 
camino a Asunción, hubo pasado a la parte oriental del río Guapay, en Santa Cruz se supo -según consta en la información de servicios de Salazar- cómo había anuencia entre los naturales de levantarse y matar a todos los que residían en esa ciudad. La respuesta de Salazar no se hizo esperar: capturó a los caciques involucrados en el levantamiento, los llevó presos a la ciudad -causando temor entre el resto de los naturales- los juzgó y los ajustició sin piedad de ninguno (2008 [1568]: 174).

Los chiriguanos estaban atentos a los movimientos de los pobladores de Santa Cruz y aprovecharon la ausencia de Chaves para preparar un ataque a la villa, al que Hernando de Salazar respondió con una ofensiva que incluyó la captura y el ajusticiamiento aleccionador de doce caciques. Los prisioneros que Salazar tomó en esa oportunidad deben haberle informado que se preparaba un ataque de los chiriguanos y otros grupos indígenas aliados contra La Barranca, donde algunos años antes había sido fundada la villa de Nueva Asunción, cerca de la cordillera de Vitupué. Por eso Hernando de Salazar envió mensajeros a La Barranca para prevenir a sus habitantes. No obstante, la comunicación se malogró porque a los mensajeros no les fue posible llegar y un tiempo después los dos hombres que sobrevivieron al asalto, Diego Guerra y Alexandre Lunberque, llegaron a Santa Cruz despojados de sus cosas, con el relato de cómo Vitupué había matado a toda la gente de La Barranca y saqueado la villa (Salazar 2008 [1568]: 183). Los chiriguanos habían tenido éxito en esta oportunidad, y sólo dos hombres sobrevivieron para contarles a sus pares cruceños los pormenores del ataque.

Probablemente los chiriguanos de la cordillera aliados con grupos chanés habían planeado destruir todas las ciudades fundadas del lado oriental del piedemonte. Luego del ataque a La Barranca, fue el turno de Santo Domingo de la Nueva Rioja, fundada por Andrés Manso en los llanos homónimos, en los alrededores del río Parapití. A los vecinos de Santa Cruz llegaron noticias de la rebelión de los indios de los llanos que servían a Andrés Manso en la que habían muerto muchos cristianos. También en esta ocasión los chiriguanos lograron su cometido, y consiguieron que Andrés Manso huyera de su real, herido, a resguardarse en las tierras altas del Perú (Salazar 2008 [1568]: 174).

El próximo objetivo fue nuevamente Santa Cruz de la Sierra. El aviso llegó a través de Redovon, un cacique la provincia de los simionos ${ }^{6}$ que llevó noticias a Santa Cruz de que los corocoronos y los de Marapi se aproximaban a la ciudad destruyendo lo que encontraban y matando a los indígenas con cotas y lanzas y vestidos de cristianos (Salazar 2008 [1568]: 174). Salazar no esperó que llegaran, sino que los fue a buscar y los desbarató en una trasnochada, castigándolos, reduciendo a los indígenas que encontró en el camino de regreso y castigando y ajusticiando a los que todavía estaban rebelados (Salazar 2008 [1568]: 174).

${ }^{6}$ Los simionos serían un grupo del sur de Santa Cruz la Vieja. Algunos autores los emparentan con los imonos, un grupo zamuco-hablante del siglo XVIII, mientras que otros los consideran parte de los payzunos. Aunque en este último caso formarían parte de la familia lingüística arawak, no puede afirmarse que haya existido una relación lingüística directa con los chanés. Esto último es importante ya que mientras Redovon, cacique de los simionos, fue quien le avisó a Salazar del inminente ataque de Vitupué, los aliados de este último eran grupos chanés (Combés 2010: 110-111, 236-239). 
Al parecer los chiriguanos fueron sorprendidos por la ofensiva de Salazar, con lo cual el ataque a Santa Cruz de la Sierra se volvió a malograr. En esa coyuntura de alzamiento generalizado de los indios de la cordillera -los de Vitupué- y de sus aliados chanés tipionos, yaconos y curiabanos ${ }^{7}$, también eran blanco de agresión aquellos pueblos que colaboraban con los españoles. Hernando de Salazar relató que el otrora aliado de los cruceños contra Manso, Vitupué, avanzaba hacia la ciudad destruyendo y matando a los indios que colaboraban con los cristianos, como sucedió con el pueblo de Moniquiono, encomendado a Juan de Eslava, que quemaron, robaron y capturaron a la gente que pudieron. A causa de esta razón los movimientos de los nativos de esas provincias se veían limitados, y no pasaban a los llanos por temor a ser atacados por los chiriguanos (Salazar 2008 [1568]: 175).

El alzamiento chiriguano era generalizado y había puesto en vilo a todos los aliados de los españoles. Nuevamente Hernando de Salazar salió a castigarlos, y el hecho de haberlos tomado por sorpresa, desprevenidos frente a su irrupción en el pueblo de Vitupué, le aseguró el triunfo en el enfrentamiento en el que hubo muchos heridos y muertos. Además cautivaron «quinientas personas y mas presas y muchas mugeres», treinta cabalgaduras, arcabuces, espadas, cotas, ropa de cristianos que los chiriguanos habían tomado en otros asaltos, que Hernando de Salazar repartió entre sus hombres. Así, de aquel despojo «quedaron encaualgados y armados y muchas personas» (Salazar 2008 [1568]: 175). Como Salazar deja ver en su información de servicios, en esta oportunidad aparecen referencias al carácter de ranchería que cobró el ataque a los chiriguanos y chanés de Vitupué.

El regreso de Chaves no revirtió el panorama de rebelión; la amenaza de que ocurriera un asalto sobre la ciudad era constante y los levantamientos cada vez más frecuentes. Las condiciones defensivas de Santa Cruz de la Sierra eran precarias. La ciudad contaba con «casas de paja y las çercas de palos y no avia otros rreparos», no había tapias, ni corrales, ni cercos que la protegieran, lo que la volvía vulnerable a posibles ataques de los pueblos de los alrededores. Ante la guerra abierta con los chiriguano se volvió necesaria la fortificación. Por eso para 1566, cuando Ñuflo de Chaves regresó de Charcas, encontró a la ciudad de Santa Cruz fortificada y con provisiones para poder hacer frente a un ataque (Salazar 2008 [1568]: 176).

Instalado nuevamente en Santa Cruz, Chaves organizó nuevas expediciones ofensivas contra los chiriguanos. En 1566 salió en dos ocasiones. En la primera aparentemente no tuvo éxito por falta de agua, y la segunda resultó en una victoria que Hernando de Salazar se atribuye al declarar que se encontraba a la vanguardia de la tropa y que fue quien entró a un pueblo de indios rebelados contra los españoles, los asaltó y los persiguió hasta el río Chinguri, donde fueron derrotados (Salazar 2008 [1568]: 176-177).

Aunque la paz pareció establecida a partir de entonces, en 1568 los itatines -guaraní-hablantes que hacía pocos años habían migrado desde el puerto de Itatín en el río Paraguay a un lugar situado a unas treinta leguas al este de Santa Cruz la Viejatendieron una trampa a Chaves y lo mataron luego de invitarlo a quedarse a descansar

7 El sufijo ono, plural chané, podría ser un indicador de la filiación etnolingüística compartida por los corocoronos, los yaconos, tipionos y curiabanos, todos aliados de los de Vitupué en los levantamientos contra las villas españolas de los llanos en 1564 (Combés 2010). 
en el pueblo. Las relaciones amistosas entre cruceños y guaraníes ya no se recompondrían: Santa Cruz de la Sierra había dejado de ser una avanzada asunceña para convertirse en un enclave de Charcas ${ }^{8}$.

\section{Palabras finales}

Llegados a este punto y poniendo en contraste las alianzas entre Chaves y sus hombres con los chiriguanos de Vitupué de 1559-1560 con el estado de guerra generalizado contra los mismos grupos que comenzó tres años después, nos preguntamos qué factores pueden explicar semejante transformación en la relación entre Chaves y sus hombres con los chiriguanos y chanés de los alrededores de Santa Cruz de la Sierra.

El movimiento pendular de los chiriguanos entre políticas de alianza y negociación, por un lado, y enfrentamientos abiertos con los conquistadores españoles, por el otro, fue señalado como uno de los rasgos distintivos de su identidad étnica. Las interpretaciones que se hicieron al respecto lo atribuyeron al carácter segmentario de su organización política, que operaba a través de la oscilación entre los acuerdos de paz y los ataques sorpresivos, y del contraste de las estrategias entre distintas parcialidades que componían en bloque a la sociedad identificada como «chiriguana». La posibilidad de hacer la guerra aun cuando ésta vulnerara acuerdos de no agresión previos fue asociada con la identidad construida en torno de la idea de ser iyambae -«sin dueño»-. La condición de dueños y hombres sin dueño también se afirmaba al interior del grupo chiriguano. En este sentido, la disparidad de las estrategias adoptadas en relación con los blancos ante las mismas situaciones les permitía prevenir el eventual surgimiento de un poder centralizado al interior mismo de su sociedad (Susnik 1968; Saignes 2007 [1990]; Combés 2005).

Pero esa dinámica interna no era desplegada en el vacío. Las aspiraciones de los interlocutores españoles con los cuales interactuaban los chiriguanos también desempeñaron un papel activo en la elección de las estrategias adoptadas por los nativos del piedemonte andino. En este sentido, debemos tener en cuenta que los españoles de Asunción contaban con vastos antecedentes de relaciones con los guaraníes del Paraguay, en las que los acuerdos, alianzas, tensiones y conflictos se desenvolvían en condiciones de aislamiento y dependencia mutua que restringían las posibilidades de dominación efectiva por parte de los conquistadores y funcionaban como mecanismos homeostáticos para mantener en pie cierta igualdad. Por intentar quebrar esa lógica fracasó el breve período legalista de Álvar Núñez, y por haber sabido adaptarse a esas condiciones Irala fue reconocido como líder por sus pares y como referente entre los nativos. Domingo Martínez de Irala hizo escuela entre sus partidarios y sucesores, como Nuflo de Chaves, pionero de la exportación de las prácticas asunceñas de matrimonios entre nativos y blancos en el piedemonte andino y de alianzas con grupos guaraní-hablantes en pos de la búsqueda de la tierra del Candire.

\footnotetext{
8 El rol de Santa Cruz de la Sierra como proveedor de indígenas para las haciendas de Charcas fue analizado en un trabajo clásico de García Recio (1988) y retomado por Coello Da Rosa (2007). Renard-Casevitz y Saignes (1988: cap. 10), por su parte, analizaron el papel desempeñado por los chiriguanos en ese vínculo comercial entre la sierra y las tierras bajas.
} 
No obstante, el asentamiento permanente de los conquistadores asunceños en la región cruceña cambió sensiblemente las condiciones del vínculo con los chiriguanos y los chané de los alrededores de Santa Cruz de la Sierra. El poblamiento del territorio cruceño por parte de la oleada conquistadora rioplatense requería de la legitimación de las autoridades coloniales de Lima y de Charcas. Santa Cruz de la Sierra, fundada a cien leguas hacia el este de la villa de La Plata, se convertiría en el primer asentamiento español en las tierras bajas de aquellas latitudes y en el único que perduró durante todo el período colonial -aún cuando a fines del siglo XVI fuera trasladado a un espacio más próximo al piedemonte-. El avance encomendado inicialmente por el virrey del Perú a Andrés Manso, con el propósito de frenar los ataques chiriguanos sobre los pueblos indígenas de las márgenes serranas, fue luego delegado a Chaves, que logró poner de su lado el favor del virrey y conseguir el nombramiento de teniente de gobernador de Mojos. Pero en la medida en que Santa Cruz de la Sierra requirió de la autorización virreinal para legitimar el asentamiento frente a la competencia de otros conquistadotes, debió ajustarse a las necesidades del centro de poder al que se debía su existencia formal. Esto gravitó ampliamente en las funciones que asumió la gobernación de Mojos, enmarcada desde entonces en la jurisdicción del virreinato del Perú y de la Audiencia de Charcas. De puesto de avance hacia la Tierra Rica pasaría entonces a ser una región de frontera, un enclave defensivo contra los chiriguano y una fuente de mano de obra para las haciendas y minas de la sierra. La inserción de esta región en el marco de la economía colonial del virreinato del Perú le implicó la asignación y asunción de nuevos roles, y modificó las relaciones entre indígenas y españoles de la región, que a partir de entonces se encontrarían abiertamente enfrentados. A este giro en la orientación de la ocupación del área cruceña atribuimos el ciclo de levantamientos de los pueblos del oriente boliviano que los españoles instalados en la nueva ciudad debieron enfrentar en la década de 1560 y que en 1568 terminó con la vida de Ñuflo de Chaves.

\section{Referencias documentales}

Colección GGV (Colección Gaspar García Viñas, Biblioteca Nacional de Buenos Aires)

Tomo 45, Doc. 914. Año 1543.

Tomo 45, Doc. 946. Año 1545.

Tomo 47, Doc. 941.

Tomo 48, Doc. 938. Año 1544.

Tomo 48, Doc. 939, Año 1543.

Tomo 48, Doc. 940. Año 1544.

Tomo 49, Doc. 946. Año 1545.

Tomo 50, Doc. 960. Año 1545.

Tomo 91, Doc. 1402. Año 1561. 


\section{Referencias bibliográficas}

Coello de la Rosa, Alexandre

2007 «Los jesuitas y las misiones de frontera del alto Perú: Santa Cruz de la Sierra (1587-1603)». Revista Complutense de Historia de América 33: 151-175.

COMBÈs, Isabelle

2005 Etnohistorias del Isoso. Chané y chiriguanos en el Chaco boliviano (siglos XVI a $X X)$. La Paz: Fundación Pieb - Instituto Francés de Estudios Andinos.

2010 Diccionario étnico Santa Cruz la Vieja y su entorno en el siglo XVI. Cochabamba: Instituto de Misionología.

«Documentos referentes...»

2008 «Documentos referentes a la fundación de Santa Cruz de la Sierra» [1561], en Desde el Oriente. Documentos para la historia del Oriente boliviano y Santa Cruz la Vieja (1542-1597), C. J. Julien, ed., pp. 94-118. Santa Cruz de la Sierra: Gobierno Municipal Autónomo.

ELLIOTT, John H.

1983 La España Imperial 1469-1716 [1963]. Barcelona: Vicens-Vives.

GANDÍA, Enrique de

1932 Historia de la conquista del Río de la Plata y del Paraguay. Los gobiernos de Don Pedro de Mendoza y Domingo de Irala. 1535-1556. Buenos Aires: Librería de A. García Santos.

García Recio, José María

1988 Análisis de una sociedad de frontera. Santa Cruz de la Sierra en los siglos XVI y XVII. Sevilla: Excma. Diputación Provincial.

Hurtado de Mendoza, Andrés, Marqués de Cañete

1921 «Carta del Marqués de Cañete a S.M dando noticia de estar el reino en paz y sosiego y haber cesado la carestía que antes había en la tierra. Habla de la expedición que manda contra los Chiriguanaes al cargo del capitán Andrés Manso» [1560], en Gobernantes del Perú. Cartas y papeles. Tomo I, R. Levillier, dir., pp. 194-213. Madrid: Sucesores de Rivadeneyra.

«Informacion de los Chiriguanaes»

2008 «Ynformaçion de los Chiriguanaes» [1571], en Desde el Oriente. Documentos para la historia del Oriente boliviano y Santa Cruz la Vieja (1542-1597), C. J. Julien, ed., pp. 222-234. Santa Cruz de la Sierra: Gobierno Municipal Autónomo.

La Gasca, Pedro de

1921 «Carta del Licenciado La Gasca al consejo de Indias sobre diversos asuntos de gobierno, entre otros el haber indicado a los Licenciados Polo y Pedro de Hinojosa que se diese a Juan Núñez del Prado autorización para fundar pueblos en el Tucumán, y que de acuerdo con ese parecer y el de los oidores le había dado nombramiento, al efecto, el 19 de junio. Insiste en la conveniencia de su vuelta a España» [1549], en Gobernantes del Perú. Cartas y papeles. Tomo I, R. Levillier, dir., pp. 194-213. Madrid: Sucesores de Rivadeneyra.

LEVILLIER, Roberto

1976 El Paititi, el Dorado y las Amazonas. Buenos Aires: Emecé. 
MartíneZ de Irala, Domingo

2008a «Relación de la jornada al norte» [1543], en Desde el Oriente. Documentos para la historia del Oriente boliviano y Santa Cruz la Vieja (1542-1597), C. J. Julien, ed., pp. 1-11. Santa Cruz de la Sierra: Gobierno Municipal Autónomo.

2008b «Carta de Domingo de Irala a Su Magestad» [1545], en Desde el Oriente. Documentos para la historia del Oriente boliviano y Santa Cruz la Vieja (1542-1597), C. J. Julien, ed., pp. 20-26. Santa Cruz de la Sierra: Gobierno Municipal Autónomo.

Renard-Casevitz, Marie-France y Thierry Saignes

1988 Al este de los Andes. Relaciones entre las sociedades amazónicas y andinas entre los siglos XVy XVII. Tomo 1: Los piedemontes orientales de los Andes centrales y meridionales: desde los patagua hasta los chiriguano. Quito: Instituto Francés de Estudios Andinos - Abya-Yala.

Roulet, Florencia

1993 La resistencia de los guarani del Paraguay a la conquista española (1537-1556). Posadas: Editorial Universitaria, Universidad Nacional de Misiones.

SAIGNES, Thierry

2007 «Guerra e identidad» [1990], en Historia del pueblo chiriguano, pp. 69-96. La Paz: Instituto Francés de Estudios Andinos - Embajada de Francia en Bolivia Plural Editores.

SAlAZAR, Hernando de

2008 «Copia de una información de servicios de Hernando de Salazar» [1568], en Desde el Oriente. Documentos para la historia del Oriente boliviano y Santa Cruz la Vieja (1542-1597), C. J. Julien, ed., pp. 170-211. Santa Cruz de la Sierra: Gobierno Municipal Autónomo.

SusNik, Branislava

1968 Chiriguanos I. Dimensiones etnosociales. Asunción: Museo Etnográfico Andrés Barbero.

1978 Los aborígenes del Paraguay I. Etnología del Chaco boreal y su periferia (siglos XVI y XVII). Asunción: Museo Etnográfico Andrés Barbero. 